
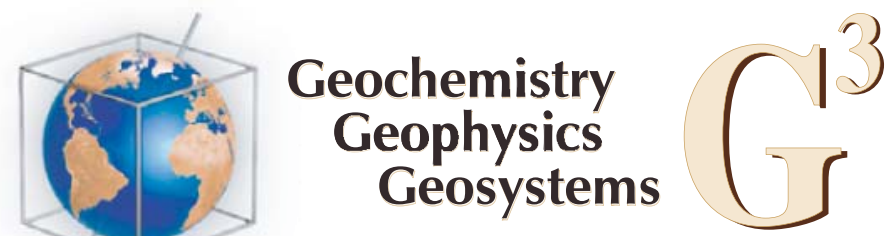

\title{
Distributed deformation ahead of the Cocos-Nazca Rift at the Galapagos triple junction
}

\author{
Deborah K. Smith and Hans Schouten \\ Department of Geology and Geophysics, Woods Hole Oceanographic Institution, Woods Hole, \\ Massachusetts 02543, USA (dsmith@whoi.edu) \\ Wen-lu Zhu and Laurent G. J. Montési \\ Department of Geology, University of Maryland, College Park, Maryland 20742, USA
}

\section{Johnson R. Cann}

School of Earth and Environment, University of Leeds, Leeds LS2 9JT, UK

[1] The Galapagos triple junction is not a simple ridge-ridge-ridge (RRR) triple junction. The Cocos-Nazca Rift (C-N Rift) tip does not meet the East Pacific Rise (EPR). Instead, two secondary rifts form the link: Incipient Rift at $2^{\circ} 40^{\prime} \mathrm{N}$ and Dietz Deep volcanic ridge, the southern boundary of the Galapagos microplate (GMP), at $1^{\circ} 10^{\prime} \mathrm{N}$. Recently collected bathymetry data are used to investigate the regional tectonics prior to the establishment of the GMP ( $1.5 \mathrm{Ma})$. South of C-N Rift a band of northeast-trending cracks cuts EPR-generated abyssal hills. It is a mirror image of a band of cracks previously identified north of C-N Rift on the same age crust. In both areas, the western ends of the cracks terminate against intact abyssal hills suggesting that each crack initiated at the EPR spreading center and cut eastward into pre-existing topography. Each crack formed a short-lived triple junction until it was abandoned and a new crack and triple junction initiated nearby. Between 2.5 and $1.5 \mathrm{Ma}$, the pattern of cracking is remarkably symmetric about C-N Rift providing support for a crack interaction model in which crack initiation at the EPR axis is controlled by stresses associated with the tip of the westward-propagating C-N Rift. The model also shows that offsets of the EPR axis may explain times when cracking is not symmetric. South of C-N Rift, cracks are observed on seafloor as old as $10.5 \mathrm{Ma}$ suggesting that this triple junction has not been a simple RRR triple junction during that time.

Components: 7200 words, 9 figures.

Keywords: East Pacific Rise; Galapagos triple junction; crack propagation; triple junction.

Index Terms: 3035 Marine Geology and Geophysics: Midocean ridge processes; 3040 Marine Geology and Geophysics: Plate tectonics $(8150,8155,8157,8158) ; 3045$ Marine Geology and Geophysics: Seafloor morphology, geology, and geophysics.

Received 9 May 2011; Revised 5 October 2011; Accepted 5 October 2011; Published 8 November 2011.

Smith, D. K., H. Schouten, W. Zhu, L. G. J. Montési, and J. R. Cann (2011), Distributed deformation ahead of the CocosNazca Rift at the Galapagos triple junction, Geochem. Geophys. Geosyst., 12, Q11003, doi:10.1029/2011GC003689. 


\section{Introduction}

[2] Seafloor bathymetric patterns at the Galapagos triple junction in the equatorial Pacific indicate that the Pacific, Cocos, and Nazca plates experience significant internal deformation where their boundaries interact [e.g., Lonsdale, 1988]. The nature of this deformation can provide important information about the state of stress near the plate boundaries and the strength of the oceanic lithosphere. The Galapagos triple junction is not a simple ridgeridge-ridge triple junction (Figure 1). The tip of the Cocos-Nazca Rift (C-N Rift) does not meet the East Pacific Rise (EPR). Instead, there are two ridge-ridge-ridge triple junctions: One south of the $\mathrm{C}-\mathrm{N}$ Rift tip at $1^{\circ} 10^{\prime} \mathrm{N}$ where Dietz Deep volcanic ridge intersects the EPR, and a second one to the north at $2^{\circ} 40^{\prime} \mathrm{N}$ where Incipient Rift intersects the EPR. Together, the EPR, Incipient Rift, C-N Rift, Dietz Deep volcanic ridge and Dietz Deep Rift bound the Galapagos microplate [e.g., Bird et al., 1999; Klein et al., 2005; Lonsdale, 1988; Searle and Francheteau, 1986; Zonenshain et al., 1980]. It has been difficult to understand the dynamics that have produced two secondary triple junctions and a microplate at the Galapagos triple junction, and several models have been put forward to explain the changing plate configurations [Klein et al., 2005; Lonsdale, 1988; Lonsdale et al., 1992; Schouten et al., 1993, 2008].

[3] Recently, Schouten et al. [2008] identified a succession of older rifts or cracks and their abandoned triple junctions with the EPR to the northeast of Incipient Rift. They suggested that the active Incipient Rift is just the latest of a sequence of southeast-trending cracks that progressively stepped southward and westward during the past 4-5 Ma, and successively accommodated some minor northsouth extension of EPR-generated crust. To explain the occurrence of these transient northern cracks and associated triple junctions, Schouten et al. [2008] suggested that the locations of the cracks are controlled by the stresses generated by two interacting cracks, one representing the tip of the large, westward propagating C-N Rift and the other the north-south trending EPR. In the crack interaction model, a zone of reduced tension (compression) develops ahead of the C-N Rift preventing it from reaching the EPR, and tensile stress maxima develop along the EPR north and south of the C-N Rift tip. The Cocos and Nazca plates may crack at the locations of the tensile maxima at the EPR, and these cracks, which are not connected to the propagating $\mathrm{C}-\mathrm{N}$ Rift, may extend eastward into the plates and develop into Incipient Rift and earlier secondary cracks. Schouten et al. [2008] found that the position of Incipient Rift corresponds closely to the location of the model tensile maximum north of the $\mathrm{C}-\mathrm{N}$ Rift and used this concept and the locations of earlier cracks to reconstruct the history of propagation of the $\mathrm{C}-\mathrm{N}$ Rift over the last 5 Ma.

[4] Mitchell et al. [2011] expanded on the Schouten et al. [2008] model to explain the formation of a sequence of closely spaced and thus quickly abandoned cracks and triple junctions that had been identified. Mitchell et al. [2011] showed that when a secondary crack is connected to the EPR, the tensile stresses at the EPR are reduced in a wide region around the crack. If the crack loses contact with the EPR (e.g., because of the fast spreading rate of the EPR, or because faults or dikes truncate the secondary crack), then the interaction between the disconnected secondary crack and the EPR produces a small scale, but high intensity version of the stress field generated by the much larger, disconnected C-N Rift. Reduced tension ahead of the secondary crack prevents it from reconnecting with the EPR, and enhanced tension is generated along the EPR slightly north or south of the detached crack. Whether a new crack forms closer to or farther from the C-N Rift depends on the distance between the detached rift and the C-N Rift. In this way, a sequence of short-lived, secondary cracks may develop that is related to the distance between the C-N Rift tip and the EPR.

[5] If the north-south trending EPR and the eastwest trending C-N Rift are the dominant cracks generating the stress field in the region, then the model predicts that secondary crack formation at the EPR should be symmetric about the C-N Rift. This is currently not the case. The Galapagos microplate has developed to the south and has been stable for $\sim 1 \mathrm{Ma}$. At the time of the Schouten et al. [2008] and Mitchell et al. [2011] studies, no bathymetry data existed to determine whether transient cracks mirroring those to the north had formed to the south prior to the establishment of the microplate.

[6] In this paper, we present multibeam bathymetry data (Figure 2), which provide a more complete view of the triple junction including the seafloor topography along the predicted locus of secondary crack formation southeast of the Galapagos microplate. The bathymetry data show cracks 


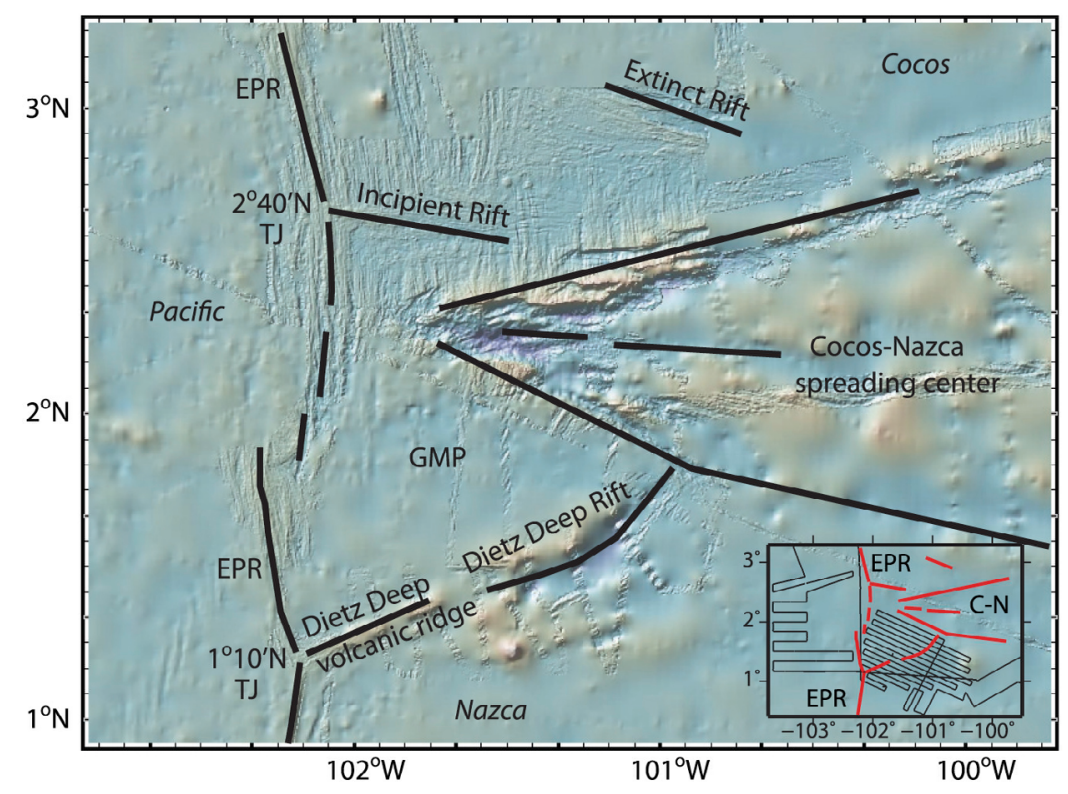

Figure 1. Map of the Galapagos triple junction in the eastern Equatorial Pacific showing satellite altimetry data and archived multibeam bathymetry data available from the Global MultiResolution Topography Data Portal at Lamont Doherty Earth Observatory. The map was generated using GeoMapApp, an exploration and visualization application developed and maintained by the Marine Geosciences Data System [Ryan et al., 2009]. Black lines: plate boundaries. Inset: track lines of R/V Atlantis Voyages 15-41 and 15-45 in 2008/2009. EPR: East Pacific Rise, GMP: Galapagos microplate, C-N: Cocos-Nazca spreading center.

morphologically similar to those observed north of the C-N Rift and confirm the applicability of the crack interaction model to explain the locations of cracks prior to $\sim 1.5 \mathrm{Ma}$. These data present an opportunity to address several outstanding questions about the dynamics of the Galapagos triple junction region and the response of the lithosphere to stress in this setting where plate boundaries are rapidly changing.

\section{Data}

[7] During R/V Atlantis Voyages 15-41 and 15-45, SeaBeam multibeam bathymetry data were obtained south of the C-N Rift over the predicted trace of transient cracks and their triple junctions with the EPR (H. Schouten and D. Smith, co-chief scientists). The track lines are shown in the inset of Figure 1. Multibeam bathymetry data were also collected over the Galapagos microplate and its boundaries, and west of the EPR (Figure 2).

[8] The bathymetry data have been combined with previously collected multibeam bathymetry data archived at the National Geophysical Data Center, the Global MultiResolution Topography Data Portal at Lamont Doherty Earth Observatory, and the Geologic Data Center at Scripps Institution of
Oceanography using MBSystem software [Caress and Chayes, 1996] to create a bathymetric grid with data points spaced at $150 \mathrm{~m}$ [Smith, 2011]. GMT software [Wessel and Smith, 1991] was used to generate the map shown in Figure 2. Seafloor lineations marking cracks, rifts and linear volcanic ridges have been identified by eye from the bathymetric map and are shown in Figure 3.

[9] Side scan data obtained from the multibeam sonar data using MBSystem software are displayed in Figure 4. The data show that Incipient Rift is characterized by high-reflectivity consistent with relatively sparse sediment cover compared to adjacent seafloor [Klein et al., 2005]. Other areas of high backscatter in the region of Incipient Rift mark faults and the young, unsedimented crust near the EPR. There is some indication of high backscatter midway along the large Extinct Rift (Figure 4). The high backscatter may be associated with the bounding scarps in part, but also appears to coincide with areas of volcanic highs just within the northern edge of the Extinct Rift graben and outside of the graben to the north and east. Seamounts with heights ranging from 200 to $800 \mathrm{~m}$ are observed in this region. The high backscatter indicates less sediment cover than the surrounding seafloor, but it is uncertain whether this indicates recent volcanism or not. 


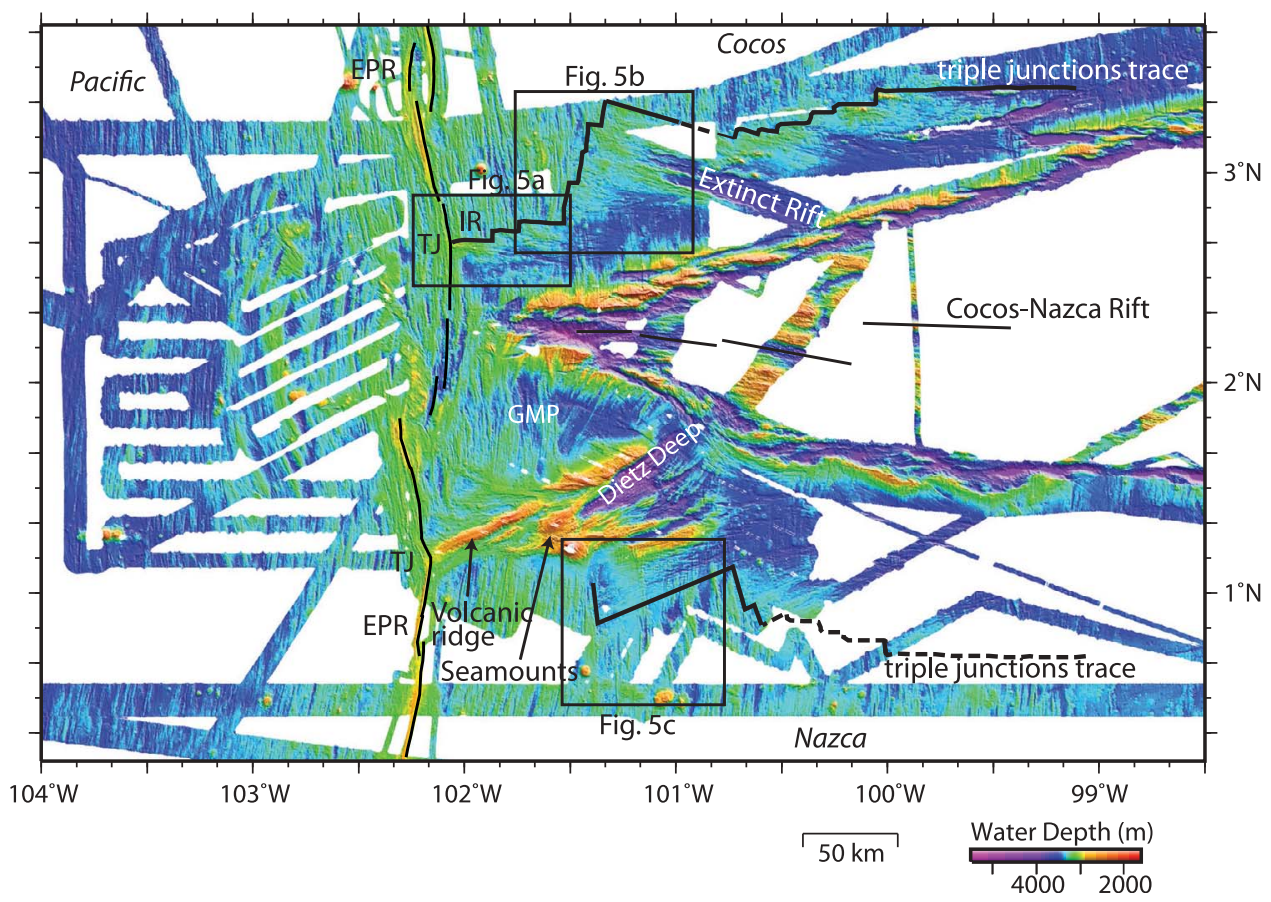

Figure 2. Bathymetric map of the Galapagos triple junction, which includes the multibeam data from R/V Atlantis Voyages 15-41 and 15-45 and all other available multibeam data archived at the National Geophysical Data Center, the Global MultiResolution Topography Data Portal at Lamont Doherty Earth Observatory, and the Geologic Data Center at Scripps Institution of Oceanography. The data were combined using MBSystem Software [Caress and Chayes, 1996]; data points are spaced at $150 \mathrm{~m}$ [Smith, 2011]. The map was generated using GMT software [Wessel and Smith, 1991]. Thin black lines: East Pacific Rise (EPR) and Cocos-Nazca Rift axes. Thick black lines: triple junctions of secondary cracks with the EPR. Dashed black lines: Interpolation of the trace of the triple junctions through data gaps (see text). Boxes: locations of data shown in Figure 5. GMP: Galapagos microplate, TJ: Triple junction, IR: Incipient Rift.

[10] South of the C-N Rift, high reflectivity in the side scan data is generally associated with the faulted crust of Dietz Deep Rift, the large volcanic edifices at the western edge of Dietz Deep Rift, and Dietz Deep volcanic ridge, the large linear ridge that meets the EPR at $1^{\circ} 10^{\prime} \mathrm{N}$ to form the southern triple junction. The only other areas of high backscatter in the region are found along abyssal hill faults and near the EPR.

\section{Structural Interpretation of Seafloor Patterns}

[11] The bathymetry data reveal a dominant band of disruption southeast of the Galapagos microplate where the broadly north-south EPR abyssal hill fabric is interrupted and cut by southwest-northeast cracking. The western edges of the cracks end at uncut abyssal hills marking the locations of their transient triple junctions with the EPR (Figures 2 and 3). Below we examine and compare in detail the transient cracks when they connected with the EPR north and south of the C-N Rift.

\subsection{Topography North of the C-N Rift}

[12] Schouten et al. [2008] used the seafloor morphology of Incipient Rift, the currently active crack and triple junction north of the $\mathrm{C}-\mathrm{N}$ Rift, (Figure 5a) to identify older cracks and their triple junctions farther to the northeast. The western end of Incipient Rift near $\sim 2^{\circ} 40^{\prime} \mathrm{N}$ consists of a volcanic high with a maximum relief of about $200 \mathrm{~m}$ above ambient seafloor [e.g., Klein et al., 2005; Lonsdale et al., 1992]. Excess volcanism blankets EPR-generated crust to the north and south of the volcanic high, extending as much as $6 \mathrm{~km}$ to the south and $2 \mathrm{~km}$ to the north, but excess volcanism does not appear to have spilled westward on to the Pacific plate. The flow extending south of the volcanic high is especially impressive; its southern scarp is about $200 \mathrm{~m}$ in relief. The volcanic high extends east for about $20 \mathrm{~km}$ after which a southeast trending graben cuts north-south-oriented 


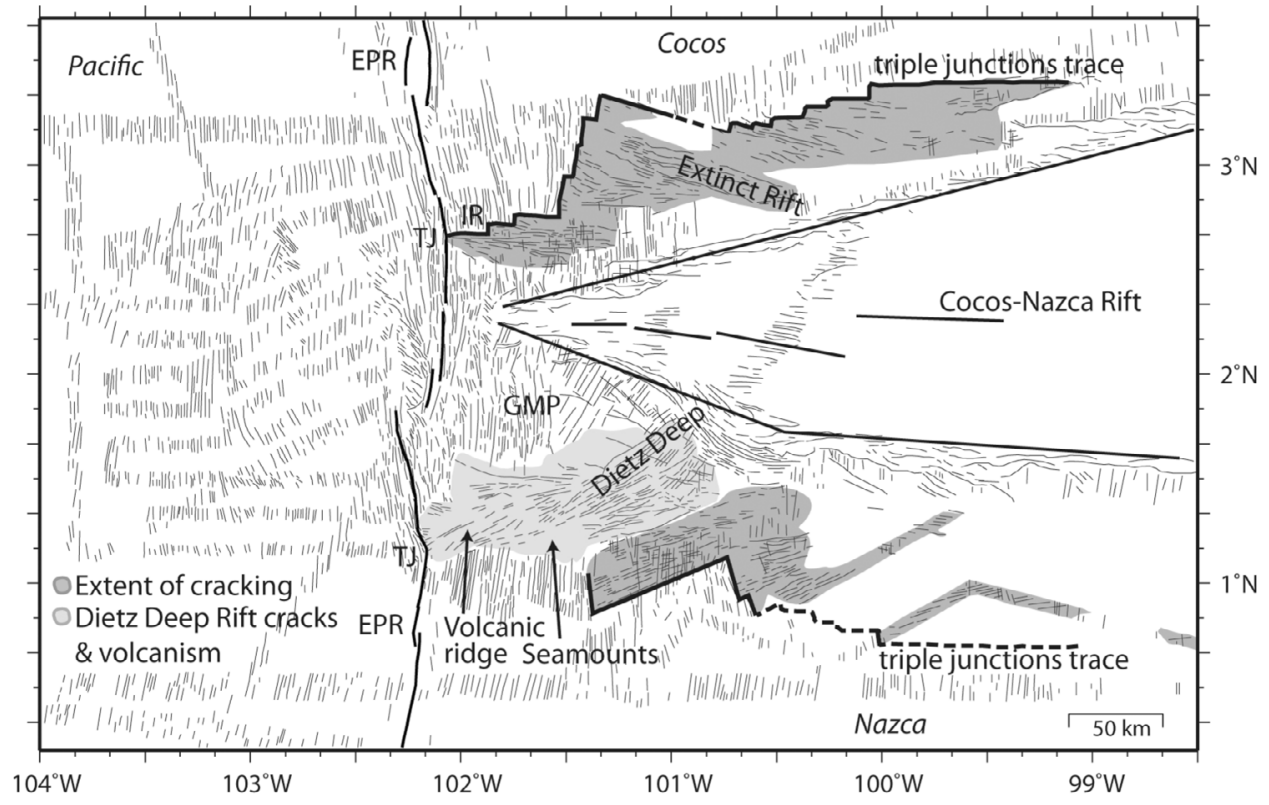

Figure 3. Seafloor lineations identified by eye from the bathymetry map of Figure 2 are shown by the light black lines. Dark gray shading: extent of cracking north and south of the Cocos-Nazca Rift, which is thought to result from stresses associated with the westward propagating Cocos-Nazca Rift. Light gray shading: area of seafloor affected by the establishment of Dietz Deep Rift, the building of two large seamounts, and the formation of Dietz Deep volcanic ridge. GMP: Galapagos microplate, EPR: East Pacific Rise, TJ: Triple junction, IR: Incipient Rift.

abyssal hills that formed at the EPR. The graben is as much as $200 \mathrm{~m}$ deep and $2 \mathrm{~km}$ wide (Figure 6). Volcanism along the deeper eastern section of Incipient Rift is limited [Klein et al., 2005]. The length of Incipient Rift from the EPR to the eastern end of the graben is about $60 \mathrm{~km}$.
[13] Schouten et al. [2008] envisioned that Incipient Rift initiated at the EPR $\sim 0.5 \mathrm{Ma}$ cracking into older seafloor to the east/southeast and cutting preexisting abyssal hill topography. The point of initiation sits about $35 \mathrm{~km}$ east of the EPR $\left(\sim 101^{\circ} 45^{\prime} \mathrm{W}\right)$. As the EPR continued to spread, the crack grew

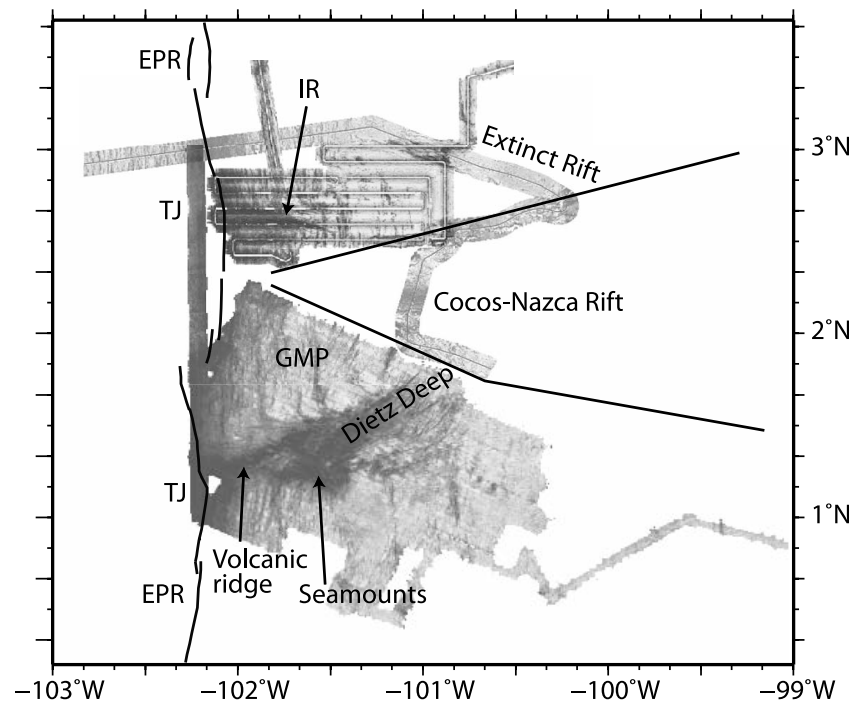

Figure 4. Side scan data derived from multibeam sonar data collected during cruises AT15-41 and AT15-45, combined with side scan data from Vancouver Leg01 [Klein et al., 2005], and DANA05 [e.g., Engels et al., 2008]. Dark: high reflectivity generally associated with low sediment cover and or fault scarps. Light: low reflectivity typically thought to indicate significant sediment cover. Black Lines: East Pacific Rise (EPR) axis and scarps of Cocos-Nazca Rift. GMP: Galapagos microplate, TJ: Triple junction, IR: Incipient Rift. 
a)

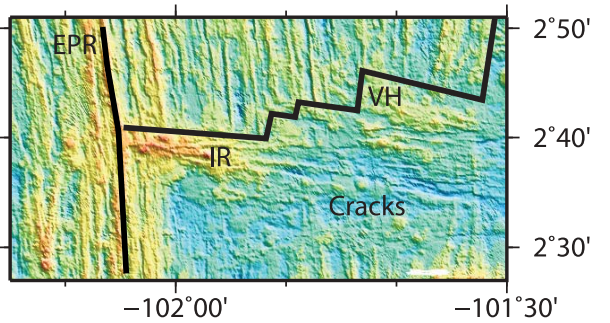

c)

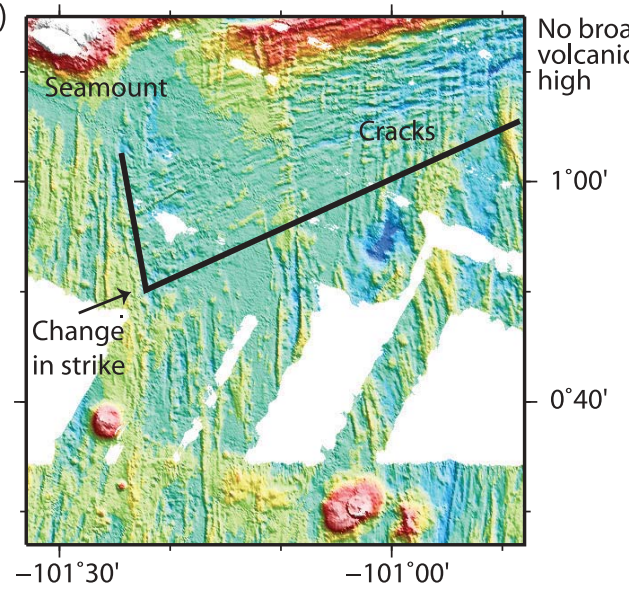

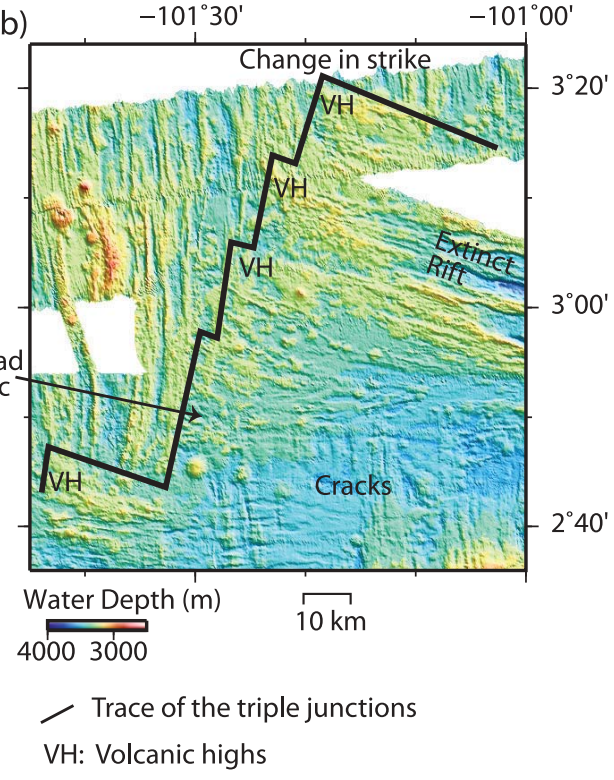
$40^{\prime}$ 


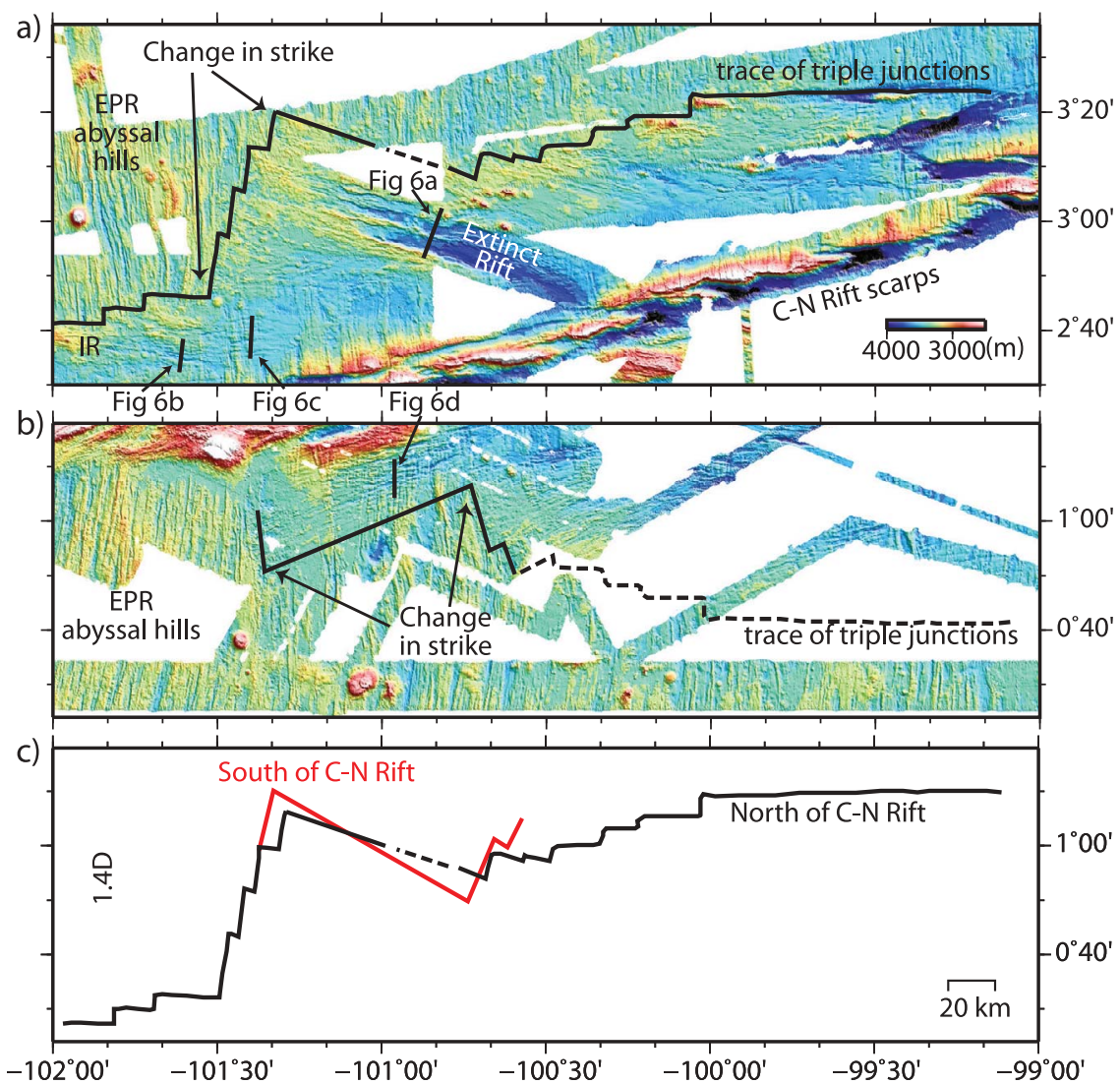

Figure 7. Shaded bathymetry of the cracking regions (a) North and (b) South of Cocos-Nazca (C-N) Rift. Thick black lines: triple junctions of secondary cracks with the East Pacific Rise (EPR). Dashed black lines: interpolation of the trace of the triple junctions through data gaps based on the opposite trace. Note the nearly synchronous change in strike of the trace near $101^{\circ} 20^{\prime} \mathrm{W}$ where the cracks jump rapidly toward the scarps of the C-N Rift. Short black lines: Locations of the profiles in Figure 6. (c) Traces of the triple junctions of secondary cracks with the EPR in the north and south cracking areas overlain. Black line: Northern trace. Red line: southern trace between 2.5 and 1.5 Ma reflected about a line oriented at $97^{\circ}$ (perpendicular to the opening direction of C-N Rift). There is notable symmetry in the traces between $100^{\circ} 40^{\prime} \mathrm{W}$ and $101^{\circ} 20^{\prime} \mathrm{W}$, after which the Galapagos microplate develops.

is more rigid and should be able to support higher structures than at the axis of the EPR, if the magma supply is sufficient.

[14] There are numerous other volcanic highs and associated lava flows northeast of Incipient Rift (Figure 5b). The western ends of these other highs end at north-south-oriented EPR abyssal hills. Similar to Incipient Rift, some of the volcanic highs rise to shallower water depths than the adjacent abyssal hill fabric. There also are places, though, where broad volcanic highs have not been constructed, and in these locations seafloor depths are typically $100 \mathrm{~m}$ deeper than the adjacent intact abyssal hill topography (Figure 5b). Graben oriented east-west and southeast-northwest extend from the eastern ends of the volcanic highs and cut north-south trending abyssal hills. The graben are typically $50-150 \mathrm{~m}$ deep and up to $1 \mathrm{~km}$ wide (Figure 6), and Schouten et al. [2008] interpreted them as extensional features bounded by smalloffset normal faults. Crack lengths from the western volcanic ends to the eastern ends of the graben range from 30 to $110 \mathrm{~km}$. Based on their similarity to Incipient Rift and low reflectivity in side scan data, Schouten et al. [2008] inferred that these features represent older tensile cracks that had once intersected the EPR as Incipient Rift does today.

[15] The trace of the northern paleo triple junctions of the cracks with the EPR is shown in Figures 2, 3 and $7 \mathrm{a}$. The strike of the trace varies notably. Near longitude $101^{\circ} 20^{\prime} \mathrm{W}$, the strike changes abruptly from westerly to southerly, and then near $\sim 101^{\circ} 30^{\prime} \mathrm{W}$ back to westerly. A more westerly trend implies a relatively stationary triple junction and continued cracking at a steady location, and a southerly trend implies that cracking and triple-junction volcanism jumped south rapidly and repeatedly. The largest graben observed is Extinct Rift [Klein et al., 2005; 
Schouten et al., 2008] (Figure 6), which is $\sim 100 \mathrm{~km}$ northeast of Incipient Rift (Figure 2). Since Extinct Rift is deeper (up to $600 \mathrm{~m}$ ), broader (up to $14 \mathrm{~km}$ ), and longer $(\sim 110 \mathrm{~km})$ than Incipient Rift, it may have been occupied for a longer period of time before it was abandoned at $\sim 1.5 \mathrm{Ma}$.

[16] Cracks several tens of $\mathrm{km}$ long, and frequently with broad volcanic highs at their western ends, are identified on the Cocos plate to about $345 \mathrm{~km}$ from the EPR or $5 \mathrm{Ma}$ (Figure 7a), assuming a total spreading rate of $135 \mathrm{~km} / \mathrm{my}$ for the Pacific-Cocos EPR [Lonsdale, 1989]. There are insufficient data to determine whether the pattern of cracking continues farther to the east.

\subsection{Topography South of the C-N Rift}

[17] Southeast of the Galapagos microplate we obtained complete bathymetric coverage of the predicted western ends of the cracks out to about 2.5 Ma. On older lithosphere, a single swath zigzags across the southern limit of the cracking. From these data, we see that about $90 \mathrm{~km}$ east of the Pacific-Nazca EPR $\left(101^{\circ} 25^{\prime} \mathrm{W}, \sim 1.5 \mathrm{Ma}\right)$, the regular north-south abyssal hill topography ends abruptly and the seafloor deepens by 50-100 m (Figures 2 and $5 \mathrm{c}$ ). East of this change the seafloor is characterized by northeast-trending, narrow volcanic ridges (a few hundreds of meters wide, a few tens of meters high) and relatively smooth topography suggestive of covering lava flows. East of the lava flows, numerous southwest-northeast oriented graben cut EPR abyssal hills. The lengths of the cracks from the western volcanic ends to the eastern limits of their graben range between $60-85 \mathrm{~km}$. The graben have depths of up to $200 \mathrm{~m}$ and widths of up to $2 \mathrm{~km}$ (Figure 6). Based on their morphologic similarity to the transient cracks north of the C-N Rift and their low reflectivity in the side scan data indicating that they are sedimented, we conclude that these features represent extinct tensile cracks. Each crack would have initiated south of the C-N Rift at the EPR and extended east/northeast cutting pre-existing abyssal hill topography. At the same time, each crack grew west/southwest to maintain contact with the EPR as it spread and as its triple junction migrated south. These cracks formed simultaneously with the cracks north of the C-N Rift.

[18] Between about 2.5 and 1.5 Ma, the trace of the triple junctions in the south cracking area is a mirror image of that in the north cracking area (Figure 7). In both areas the orientations of the cracks are inward toward the scarps of the $\mathrm{C}-\mathrm{N}$
Rift. The change in strike of the trace of the triple junctions from westerly to southerly toward the $\mathrm{C}-\mathrm{N}$ Rift in the north cracking area is matched in the south cracking area (in this case from westerly to northerly) at nearly the same time (1.5 Ma, $\left.\sim 101^{\circ} 20^{\prime} \mathrm{W}\right)$. Although cracking still continues in the north, the generation of rapidly jumping cracks in the south cracking area appears to have ceased when the large scarps and graben associated with the start of Dietz Deep Rift were established.

[19] From multibeam bathymetry data collected during our transit to the Galapagos Islands and other archived multibeam bathymetry data, cracks oriented southwest-northeast can be identified on crust as old as $10.5 \mathrm{Ma}$ at distances less than about $100 \mathrm{~km}$ from the southern scarps of the C-N Rift. The data are insufficient, however, to characterize fully the pattern of cracking east of about $100^{\circ} 30^{\prime} \mathrm{W}$.

\subsection{Traces of the Northern and Southern Transient Triple Junctions}

[20] Interruptions of the EPR-generated north-south trending abyssal hill topography have been our main guide in identifying the western limits of the cracks in the north and south cracking areas (Figure 5). In the north, broad volcanic highs with flows extending from them are observed at the western ends of the cracks in most places. In the south cracking area there is little constructional volcanism only what appears to be blanketing flows, and the transition from EPR-generated abyssal hills to cracking is sharper, marked by an increase in water depth of 50-100 m.

[21] Figures $7 \mathrm{a}$ and $7 \mathrm{~b}$ shows our identification of the traces of the triple junctions in the north and south cracking regions lined up by longitude. We have continued the traces as dashed lines through gaps in the data using the opposite trace as a guide for the shape. In Figure 7c, the traces are shown together. The southern trace between 2.5 and 1.5 Ma has been reflected about a line oriented at $97^{\circ}$ (perpendicular to the opening direction of the C-N Rift). As described above, there is notable symmetry in the traces of the triple junctions during this time.

\section{Discussion}

[22] In this paper we have documented the presence of extinct, secondary cracks south of the C-N Rift prior to the establishment of the Galapagos 
microplate. The structural elements of these southern cracks are similar to those described by Schouten et al. [2008] for cracks north of the C-N Rift: The western ends of the cracks meet intact EPR-generated abyssal hill topography and the eastern ends of the cracks cut EPR-generated abyssal hills producing a distinctive cross hatched topography with remnants of cut abyssal hills lining up approximately north-south. These observations are consistent with the idea that each of the secondary cracks initiated at the EPR to form a short-lived triple junction with the EPR and extended eastward into pre-existing abyssal hill topography. Subsequently, each of the cracks became detached from the EPR and abandoned and a new crack formed nearby [Mitchell et al., 2011]. The western ends of the cracks, therefore, mark the locations of abandoned triple junctions of the cracks with the EPR.

[23] In the north cracking area, volcanic highs have been built on top of the western ends of most of the old cracks. The highs are similar to the broad volcanic ridge observed at the western end of Incipient Rift the presently active triple junction. The eruptions at Incipient Rift are likely fed by the EPR melting regime [Hanna et al., 2003], and we infer that the source of the lavas that built the older volcanic highs north of the C-N Rift was the same. Seafloor depths of these volcanic highs are comparable to those of the abyssal hill topography that they end at. Where there are no volcanic highs, such as near $2^{\circ} 50^{\prime} \mathrm{N}, 101^{\circ} 30^{\prime} \mathrm{W}$ (Figure 5b), the seafloor is about $100 \mathrm{~m}$ deeper than the adjacent intact abyssal hill topography. This implies that magma supply to the western ends of the cracks was sufficient to build constructional volcanic edifices with heights of up to $100 \mathrm{~m}$ in most places.

[24] In the south cracking area, there is no constructional volcanism near the western ends of the cracks. The relatively flat morphology of this area suggests an abundance of low-lying lava flows that have blanketed most of the abyssal hills. It also suggests that the chemistry of the lavas and/or eruption variables were different in this region from the north cracking area. The construction of the large seamounts at about 1.5 Ma [Lonsdale, 1988], one of which reaches up to a water depth of $1600 \mathrm{~m}$, and the construction of Dietz Deep volcanic ridge with a relief of $1000 \mathrm{~m}$, suggests a mantle thermal anomaly in the region. The melt that fed the seamounts may have contributed both to the production of blanketing lavas at the western ends of the cracks and the overall melt supply to the ridge axis. Unfortunately, there are no rock samples from the seamounts or the currently active Dietz Deep volcanic ridge to investigate this further.

[25] The seafloor in both the north where there are no constructional volcanic ridges and south cracking regions is roughly $100 \mathrm{~m}$ deeper than adjacent uncracked seafloor of similar age. Some of the seafloor deepening at the western ends of the cracks may be explained by thinning of the lithosphere caused by minor north-south extension [e.g., McKenzie, 1978]. In addition, the cracks themselves may have enhanced cooling of the crust and lithosphere adding to the normal subsidence rate of the crust with age.

[26] Near the western ends of the cracks in both cracking areas there is little evidence of the original EPR-generated abyssal hill topography. Cracking by itself cannot explain the destruction of abyssal hill topography since it has not completely destroyed the abyssal hills at the eastern ends of the cracks. In the north, the constructional volcanism may mask most of the underlying abyssal hill topography. In the south, the low-lying flows would have to be substantial enough to fill the cracks and cover the abyssal hill topography. Although the styles of volcanism are completely different it appears that significant volcanic eruptive activity accompanied the cracking in both areas.

[27] The symmetry in cracking north and south of the $\mathrm{C}-\mathrm{N}$ Rift prior to the development of the Galapagos microplate adds strong support for the Schouten et al. [2008] crack interaction model. In this model, the EPR is assumed to be a stress free deformable boundary, which bends slightly in response to stresses associated with the tip of the large, westward propagating C-N Rift. Secondary cracks will initiate north and south of the C-N Rift tip at bends in the EPR, the location of stress maxima. The secondary cracks that develop at the EPR will extend outward into the plate, continuously curving toward the scarps of the C-N Rift [Mitchell et al., 2011].

[28] The symmetry in cracking between 2.5 and $1.5 \mathrm{Ma}$ is remarkable, especially near $101^{\circ} 20^{\prime} \mathrm{W}$ where the excursions of both of the traces of the triple junctions toward the C-N Rift appear synchronous (Figure 7c). Symmetry breaks down with the establishment of the large scarps and graben that make up the southeast boundary of the Galapagos microplate. Symmetry also breaks down on older crust to the east between about $100^{\circ} 35^{\prime} \mathrm{W}$ and $100^{\circ} 45^{\prime} \mathrm{W}$ where another rapid-jumping sequence 
of cracks is observed in the south cracking region. This pattern is not matched in the north cracking region. It could be that the stress response to changing the distance between the EPR and the tip of the C-N Rift is not always symmetric, as will be the case for an asymmetric EPR.

[29] The current shape of the EPR is not symmetric about the C-N Rift, as assumed in the model. An overlapping spreading center with a $15 \mathrm{~km}$ eastwest offset has formed at $1^{\circ} 50^{\prime} \mathrm{N}$ (Figure 2), and Lonsdale [1989] has suggested that there have been several episodes of migrating offsets along the Pacific-Nazca EPR in the recent past. In order to assess the importance of an asymmetric geometry of the EPR, we have modified the crack interaction model to include a right stepping offset of the EPR south of the C-N Rift, similar to what is observed today (Figure A1). The model is described in detail in the Appendix.

[30] We find that the two overlapping EPR limbs interact to form a well-studied zone of high stress that drives ridge propagation and migration of the ridge offset [Pollard and Aydin, 1984]. The C-N Rift tip interacts with the EPR in a manner similar to that described in the study by Schouten et al. [2008]. At the EPR, tension is reduced in front of the C-N Rift tip and is enhanced to the north and south along the EPR. What is different, however, is that the region of stress enhancement at the EPR south of the C-N Rift tip is subdued because of the ridge offset (Figure A2). Thus it is possible that the asymmetry in cracking observed since about 1.5 Ma may be explained in part by the presence of a ridge offset south of the C-N Rift tip. The recent evolution of the EPR and the establishment of the Galapagos microplate will be the subject of a second paper.

[31] It appears from existing bathymetry data south of the C-N Rift that cracks have been produced for as long as $10.5 \mathrm{Ma}$ and limited to within about $100 \mathrm{~km}$ distance to the southern scarps of the C-N Rift. If persistent cracking at the Galapagos triple junction is indeed a result of the large, propagating C-N Rift that fails to connect to the EPR, then the cracks observed in older seafloor suggest that this triple junction has not been a proper ridge-ridgeridge triple junction for at least the last 10.5 Ma.

[32] What about other triple junctions? The Rodriguez triple junction in the Indian Ocean appears to have a simpler geometry than the Galapagos triple junction: The Central, Southeast, and Southwest Indian ridges meet to form a ridge-ridge-ridge triple junction. At the Rodriguez triple junction there is no seafloor evidence for secondary cracks [e.g., Mitchell and Parson, 1993; Sauter et al., 1997]. Nonetheless, the simple crack interaction model predicts that if the slow-spreading Southwest Indian Ridge detaches from the triple junction it will not be able to reconnect because a zone of reduced tension is created in front of its tip. Mitchell [2010] concluded, however, that because of the difference in azimuth between the Central and Southeast Indian ridge, which produces a kink in the axis and focuses the tensile stresses there, that even if the Southwest Indian Ridge detaches from the triple junction, a new crack will generate at the former triple junction making it easier to reconnect. It is clear that the position and geometry of the major plate boundaries that meet at a ridgeridge-ridge triple junction must play a major role in controlling the stability and the production of secondary cracks.

\section{Conclusions}

[33] We report the presence of a band of parallel, southwest-northeast oriented cracks that formed south of the C-N Rift prior to the development of the Galapagos microplate at the Galapagos triple junction. The band of cracks is a mirror image of a band of cracks on the same age crust north of the C-N Rift described by Schouten et al. [2008]. The bathymetric relations show that each crack initiated at the EPR and cut eastward into pre-existing abyssal hill topography as Incipient Rift (the current active crack to the north) does today. Each crack maintained contact with the fast spreading EPR to form a triple junction until it became detached from the EPR, was abandoned, and a new parallel crack and triple junction formed nearby [Mitchell et al., 2011].

[34] Between about 2.5 and 1.5 Ma, the pattern of secondary cracking is symmetric north and south of the C-N Rift. The symmetry of the cracks about the $\mathrm{C}-\mathrm{N}$ Rift provides support for a crack interaction model in which the locations of secondary cracks initiating at the EPR are controlled by stresses associated with the tip of the dominant, westward propagating C-N Rift that does not meet the EPR [Schouten et al., 2008]. Symmetry is not always perfect though, and a crack interaction model was tested in which the EPR has a right stepping offset south of the C-N Rift similar to what is observed today. The model results show that because of the offset, the region of stress enhancement at the EPR south of the C-N Rift tip is subdued. It is possible that asymmetry in secondary crack formation may 


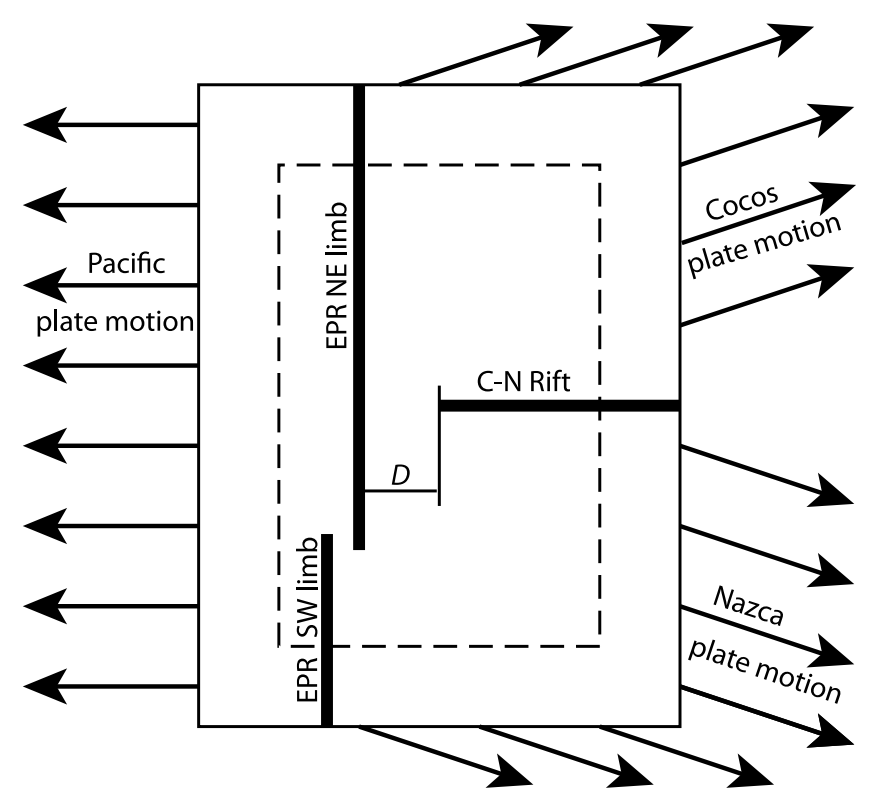

Figure A1. Model geometry for calculating stress interaction between the Cocos-Nazca $(\mathrm{C}-\mathrm{N})$ Rift tip and the East Pacific Rise (EPR). The overlapping ends of the EPR are located at $(-0.4,-1.6)$ and $(0,-1.8)$, and the tip of the C-N Rift is at $(1,0)$, where all the distances are scaled by $D$, the distance between the C-N Rift tip and the EPR. Plate motion is imposed on all the sides of the model, as shown by the arrows. Stretching in the $\mathrm{x}$-direction is three times faster than in the y-direction. The dashed line marks the region visualized in Figure A2.

be explained in part by the presence of migrating ridge offsets.

[35] Secondary cracks are observed south of the $\mathrm{C}-\mathrm{N}$ Rift on seafloor as old as 10.5 Ma suggesting that the tip of the C-N Rift has not connected to the EPR in a true ridge-ridge-ridge geometry since that time. These observations provide new constraints on the response of the lithosphere to stress in a setting where plate boundaries are rapidly changing.

\section{Appendix A1}

[36] In this appendix we extend the crack interaction model of Schouten et al. [2008] to assess the effect of an overlapping spreading center at the EPR south of the C-N Rift tip (Figure A1). The geometry is similar to the current geometry of the ridge axis. The model considers a thin elastic plate with uniform thickness stretched by the relative motions of the Cocos, Nazca, and Pacific plates. The assumption of uniform plate thickness has been investigated by Schouten et al. [2008] and Mitchell et al. [2011] who found that adding plate thickening mainly enhances the stress at the EPR without significantly changing the stress maxima locations.

[37] The C-N Rift and the limbs of the EPR are taken to be straight. The offset and slightly overlapping limbs of the EPR are stress-free boundaries (thin ellipses). For simplicity, we also represent the $\mathrm{C}-\mathrm{N}$ Rift as a stress-free boundary. There may be some resistance at the slower spreading $\mathrm{C}-\mathrm{N}$ ridge axis, but it has little effect on the stress patterns if the C-N Rift is assumed to be 100 times or more weaker than the rest of the plate. Because of this and the fact that it is not clear what resistance to add to the model, we prefer following the simplifying assumption of a stress-free crack and infer that the C-N Rift does not offer resistance to rifting.

[38] In the model, the opening rate of the EPR, $V_{E P R}$, is three times the opening rate of the C-N Rift, $V_{C N R}$. All lengths are scaled by $D$, the length of the gap between the C-N Rift tip and the EPR. If there was no $\mathrm{C}-\mathrm{N}$ Rift, divergence of the Cocos and Nazca plates would produce a uniform stress $\sigma_{0}=E V_{C N R} \delta t / L_{y}$, with $E$ the Young's modulus, $L_{y}$ the length of the model parallel to the EPR, and $\delta t$ the duration of stretching. The stress field in this model is scaled by $\sigma_{0}$.

[39] Results from the model yield variations in tension enhancement, $T$, defined as the first principal stress divided by the reference stress $\sigma_{0}$. Cracking develops when the first principal stress exceeds a critical value [Erdogan and Sih, 1963], so that $T$ indicates where cracks are likely to form. Because the plate is continuous between the various 

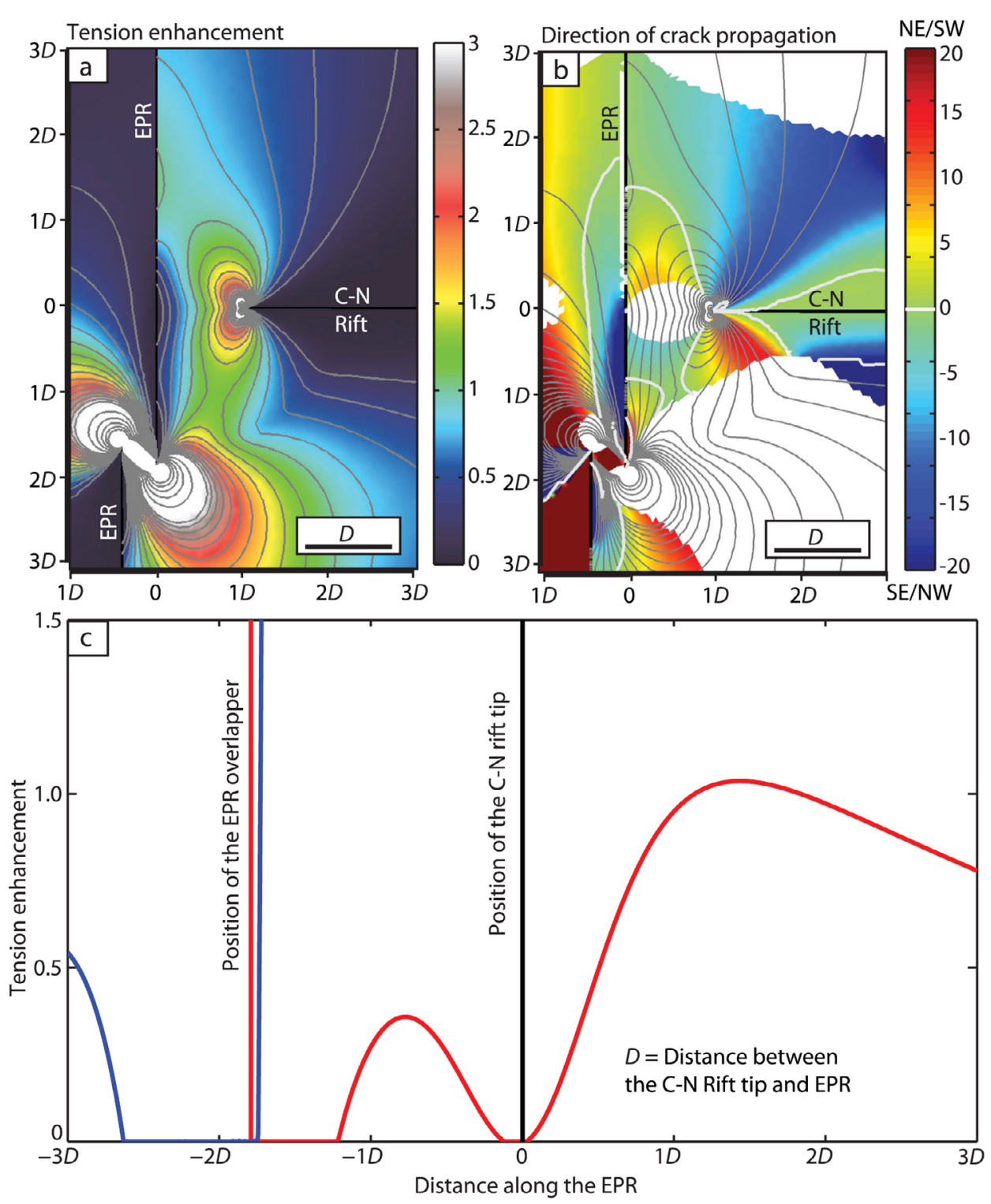

Figure A2. Stress enhancement resulting from the interaction of cracks with the geometry of the Cocos-Nazca (C-N) Rift and East Pacific Rise (EPR) shown in Figure A1. Tension enhancement, T, is the first principal stress scaled by $\sigma_{0}$, the value expected from the divergence of the Cocos and Nazca plates with a continuous EPR and no C-N Rift. Lengths are scaled by $D$, the distance between the C-N Rift tip and the EPR. (a) Map of tension enhancement near the triple junction. Contours are every 0.2 for $0 \leq T \leq 3$ and every 1 for $3 \leq T \leq 8$. (b) Direction of crack propagation (degrees anticlockwise from E-W azimuth) based on the orientation of the most compressive stress $\sigma 3$. Regions where $\sigma 3$ is vertical are marked in white. Contours of Figure A2a are repeated for reference. White contours show where direction of propagation is 0 (i.e., E-W). (c) Profiles of tension enhancement along the EPR north and south of C-N Rift as a function of $D$. Red: NE limb of the EPR; Blue: SW limb of the EPR. Stress along the $\mathrm{NE}$ limb is asymmetric about the C-N Rift (located at 0) because of the presence of the EPR offset. The higher amplitude of the peak near 1.4D north of the C-N Rift indicates that cracking at the EPR may be limited to the north if there is a ridge offset located south of the C-N Rift.

cracks, stress is increased at the ends of the cracks (Figure A2a). The tension enhancement is higher at the ends of the two overlapping limbs of the EPR than at the C-N Rift tip because of the faster spreading rate of the EPR.
[40] Figure A2b shows the direction of crack propagation based on the orientation of the most compressive stress $\sigma 3$. Regions where $\sigma 3$ is verti$\mathrm{cal}$, indicating that both in-plane stresses are in tension, are marked in white. Profiles of tension 
enhancement along the EPR north and south of the C-N Rift plotted as a function of $D$ are shown in Figure A2c. The results show that stress along the northeast limb of the EPR is asymmetric about the C-N Rift because of the presence of the EPR offset.

\section{Acknowledgments}

[41] We would like to thank the crew of the R/V Atlantis for their tireless effort to collect the best data possible. We would also like to thank D. Caress for his help in using MBSystem. We thank Suzanne Carbotte and an anonymous reviewer for their very helpful comments on the first draft of the manuscript. HS was supported by the U.S. National Science Foundation (NSF) grant OCE-0751831, DS by NSF grant OCE-1028537, WZ by NSF grant EAR-1056317, and LM by NSF grant EAR-0911151.

\section{References}

Bird, R. T., S. F. Tebbens, M. C. Kleinrock, and D. F. Naar (1999), Episodic triple-junction migration by rift propagation and microplates, Geology, 27, 911-914, doi:10.1130/ 0091-7613(1999)027<0911:ETJMBR>2.3.CO;2.

Caress, D. W., and D. N. Chayes (1996), Improved processing of Hydrosweep DS multibeam data on the R/V Maurice Ewing, Mar. Geophys. Res., 18, 631-650, doi:10.1007/ BF00313878.

Engels, M., U. Barckhausen, and J. S. Gee (2008), A new towed marine vector magnetometer: Methods and results from a Central Pacific cruise, Geophys. J. Int., 172, 115-129, doi:10.1111/j.1365-246X.2007.03601.x.

Erdogan, F., and G. C. Sih (1963), On the crack extension in plates under plane loading and transverse shear, J. Basic Eng., 85D, 519-527.

Hanna, H. D., E. M. Klein, D. K. Smith, and W. Zhu (2003), Along-axis geochemical variations in basaltic glasses from the Incipient rift adjacent to the East Pacific Rise at $2^{\circ} 40^{\prime} \mathrm{N}$, Eos Trans. AGU, 84(46), Fall Meet. Suppl., Abstract V12C-0601.

Klein, E. M., D. K. Smith, C. M. Williams, and H. Schouten (2005), Counter-rotating microplates at the Galapagos triple junction, eastern equatorial Pacific Ocean, Nature, 433, 855-858, doi:10.1038/nature03262.

Lonsdale, P. (1988), Structural patterns of the Galapagos Microplate and evolution of the Galapagos triple junction, J. Geophys. Res., 93, 13,551-13,574, doi:10.1029/JB093iB11p13551.
Lonsdale, P. (1989), The rise flank trails left by migrating offsets of the equatorial East Pacific Rise axis, J. Geophys. Res., 94, 713-743, doi:10.1029/JB094iB01p00713.

Lonsdale, P., N. Blum, and H. Puchelt (1992), The RRR triple junction at the southern end of the Pacific-Cocos East Pacific Rise, Earth Planet. Sci. Lett., 109, 73-85, doi:10.1016/0012821X(92)90075-7.

McKenzie, D. (1978), Some remarks on the development of sedimentary basins, Earth Planet. Sci. Lett., 40, 25-32, doi:10.1016/0012-821X(78)90071-7.

Mitchell, G. A. (2010), Stability of ridge-ridge-ridge triple junctions based on the mechanics of rift interation: The northern Galapagos and Rodriguez triple junctions, thesis, Univ. of Maryland, College Park.

Mitchell, N. C., and L. M. Parson (1993), The tectonic evolution of the Indian Ocean triple junction, anomaly 6 to present, J. Geophys. Res., 98, 1793-1812, doi:10.1029/92JB00582.

Mitchell, G. A., L. G. J. Montési, W. Zhu, D. K. Smith, and H. Schouten (2011), Transient rifting north of the Galápagos triple junction, Earth Planet. Sci. Lett., 307(3-4), 461-469, doi:10.1016/j.epsl.2011.05.027.

Pollard, D. D., and A. Aydin (1984), Propagation and linkage of oceanic ridge segments, J. Geophys. Res., 89, 10,017-10,028, doi:10.1029/JB089iB12p10017.

Ryan, W. B. F., et al. (2009), Global multi-resolution topography synthesis, Geochem. Geophys. Geosyst., 10, Q03014, doi:10.1029/2008GC002332.

Sauter, D., V. Mendel, C. Rommevaux-Jestin, P. Patriat, and M. Munschy (1997), Propagation of the South West Indian Ridge at the Rodrigues triple junction, Mar. Geophys. Res., 19, 553-567, doi:10.1023/A:1004313109111.

Schouten, H., K. D. Klitgord, and D. G. Gallo (1993), Edge-driven microplate kinematics, J. Geophys. Res., 98, 6689-6701, doi:10.1029/92JB02749.

Schouten, H., D. K. Smith, L. Montesi, W. Zhu, and E. M. Klein (2008), Cracking of lithosphere north of the Galapagos triple junction, Geology, 36, 330-342, doi:10.1130/ G24431A.1.

Searle, R. C., and J. Francheteau (1986), Morphology and tectonics of the Galapagos triple junction, Mar. Geophys. Res., $8,95-129$.

Smith, D. (2011), Grid(s) of multibeam bathymetry at Galapagos Triple Junction, Integr. Earth Data Appl., Palisades, New York, doi:10.1594/IEDA/100005.

Wessel, P., and W. H. F. Smith (1991), Free software helps map and display data, Eos Trans. $A G U, 72(41), 441$, doi:10.1029/90EO00319.

Zonenshain, L. P., L. I. Kogan, L. A. Savostin, A. J. Golmstock, and A. M. Gorodnitskii (1980), Tectonics, crustal structure and evolution of the Galapagos triple junction, Mar. Geol., 37, 209-230, doi:10.1016/0025-3227(80)90102-4. 